\title{
A Pontifícia Universidade Católica de Campinas e a produção científica'
}

\author{
The Pontifícia Universidade Católica de Campinas and \\ the scientific production
}

Adilson Luiz PINTO2

\begin{abstract}
RESUMO
Esta pesquisa analisa a produção científica da Pontifícia Universidade Católica de Campinas durante o período de 1995 a 2002. O corpus do estudo são as pesquisas realizadas pelos docentes dos Programas de Pós-graduação Stricto Sensu, sejam elas produção individual ou produção realizada pelos grupos de pesquisa. Tem como objetivos (i) analisar a vinculação da produção dos docentes da Pós-graduação Stricto Sensu com as linhas de pesquisas e (ii) desenvolver parâmetros para analisar a produção científica institucional. Quanto ao método para o estudo dessa produtividade, adotou-se a cienciometria; utilizou-se a análise quantitativa, cujos resultados foram obtidos através de uma intensa investigação (i) da produção indexada no Currículo Lattes de cada docente e (ii) das atividades realizadas nos grupos de pesquisa. Os parâmetros foram desenvolvidos especificamente para analisar as pesquisas realizadas na PUC-Campinas, não fugindo da realidade da instituição; para tal, as questões trabalhadas foram: (a) a relação da publicação com os propósitos/temática do grupo de pesquisa; (b) a amplitude da pesquisa; (c) o tipo de pesquisa realizada; (d) a veiculação das pesquisas; (e) a análise da produtividade individual de cada docente. Os resultados do estudo indicam um crescimento no número de pesquisas publicadas durante o período estudado (1995/2002), Em todos os pontos a evolução foi evidente, com números surpreendentes, mesmo considerandose os números modestos na produção docente de artigos em periódicos (499 artigos), com exceção do número maior relativo aos docentes da Pós-graduação em Psicologia. Os resultados indicam que as atividades de pesquisa científica nas áreas de pós-graduação são relevantes e têm um significado social capaz de justificar a existência de tais Programas, a sua preservação e o seu desenvolvimento futuro.
\end{abstract}

Palavras-chave: produção científica na PUC-Campinas; literatura branca e cinzenta; pós-graduação Stricto Sensu; grupos de pesquisa; Currículo Lattes.

\footnotetext{
ABSTRACT

This research analyses the scientific production of faculty members at the Graduate Programs (Strictu Sensus) of the Pontifícia Universidade Católica de Campinas during the period of 1995 to 2002. The study took into account, each individual's production, as well as the production carried through research groups. The objectives were (i) to analyze the connections of the graduate faculty production with lines of research; (ii) and to develop parameters to analyze the institutional scientific production. The method adopted to study the scientific productivity was the scientometrics, which entailed a quantitative analysis resulting from intense investigations of (i) the production index of each faculty's Lattes Curriculum, and (ii) the activities carried on in the research groups.

1 Artigo elaborado a partir da dissertação de A.L. PINTO, intitulada "Produção científica na PUC-Campinas no período de 1995 a 2002 ". Pontifícia Universidade Católica de Campinas, 2004. Orientação: Profa. Dra. Vera Sílvia Marão Beraquet.

2 Doutorando em Documentação, Universidad Carlos III de Madrid. Madrid, España. E-mails: <100059034@alumnos.uc3m.es>; <didis98@hotmail.com>.

Recebido em 29/3/2005 e aceito para publicação em 4/8/2005.
} 
The analysis parameters were specifically developed to examine the research produced at the Pontifícia Universidade Católica de Campinas, considering the institution's reality; thus, the tasks to be performed were (a) to relate the publication with the proposal/thematic of the research group; and to analyze (b) the research's breadth, (c) the research's type, (d) the research's dissemination, and (e) faculty member's individual productivity. The results indicated relative growth in the studied period; evolution was evident, given the overall surprising numbers, and in spite of the low numbers of articles published in periodicals (499 articles), exception made to the higher number produced by faculty of the Graduate Program in Psychology. In conclusion, this research demonstrates the excellence of Pontifícia Universidade Católica de Campinas Graduate Programs, whose relevant results in scientific research, with their social meaning, justify not only the existence and preservation of such Programs, but also their near future development.

Key words: scientific production at PUC-Campinas; research publications; white and gris literature; graduate programs (in Stricto Sensu); research groups; Lattes curriculum.

\section{N T R O D U Ç Ã O}

Este estudo está centrado na produção científica dos Programas de Pós-graduação da Pontifícia Universidade Católica de Campinas - Mestrados em Biblioteconomia e Ciência da Informação, Urbanismo, Filosofia, Educação e Psicologia, e Doutorado em Psicologia, entre os anos de 1995 a $2002^{3}$. É importante destacar que esta investigação partiu do pressuposto em alguns marcos em estudos métricos, como o trabalho de Garfield (1955), que enfoca a normalização das revistas, tendo como bases os índices Science Citation Index e Social Science Citation Index do Institute for Scientific Information (ISI); o estudo de Price (1963) sobre o crescimento exponencial das ciências; e o de Schwartzman (1993), que descreve os caminhos do desenvolvimento nacional através da produção científica e ressalta a importância de publicar-se em revistas indexadas em bases de conhecimento, tais como os citados Indexes do ISI, o "Latindex" e "SciELO" para o Brasil. Porém, fazem-se necessários estudos circunscritos aos currículos, estudo a partir do Currículo Lattes do CNPq, dos docentes de cada instituição, como forma de gerar indicadores que, sendo também exaustivos, tenham um custo menor que o das bases de dados internacionais, tais como as do ISI.

Neste sentido, procuramos ter como objeto de estudo uma instituição de tradição, com características próprias e com facilidade de acesso às informações sobre suas atividades produtivas. Devemos assinalar que este tipo de investigação seria facilitado se a PUC-Campinas divulgasse sua produção anual em pesquisas na forma de memórias.

A PUC-Campinas no ano de 2002 contou com um total 18.848 alunos em 41 cursos de graduação, 1.360 em 29 cursos de Mestrado, Doutorado, Especialização e Aperfeiçoamento, 1.038 professores e 1.414 funcionários (PUC-Campinas, 2002). De todo universo exposto, estudamos somente os professores dos programas de pós-graduação (Mestrado e Doutorado), um total de 56 docentes.

Nos últimos anos, a PUC-Campinas logrou uma produção científica de qualidade, em forte relação com seus projetos e grupos de pesquisa, principalmente no período de investigação deste estudo (1995 a 2002). Além disso, a instituição teve uma evolução significativa em relação aos grupos de pesquisas, principalmente nos anos de 1996 até 1998, com pelo menos um grupo por ano; entretanto, em 1999 não foi constatado nenhum novo grupo consolidado. Nos anos de 2000 a 2002, novos grupos voltaram a consolidar-se, com um alto crescimento no último ano de estudo.

Na parte prática, foram estudados 451 artigos publicados em periódicos nacionais (por 10 docentes em Urbanismo; 8 docentes em Filosofia; 17 docentes em Educação; 6 docentes em Ciências da Informação; e 15 docentes em Psicologia), sendo 5,76\%

\footnotetext{
3 Foram identificados somente os docentes que faziam parte dos Programas de Pós-graduação no ano de 2002; porém, realizou-se uma investigação da participação científica de cada um desses docentes na Instituição desde 1995. A pesquisa não pôde ser realizada com ex-professores (no período estudado de 1995 a 2002) pela falta de informação dos Programas, que consideraram estas informações como "não públicas" com exceção do Programa de Ciência da Informação e Biblioteconomia, que colaborou com todas as informações exigidas para esta investigação. Entretando, a fim de estudarmos a produção de todos os programas com igualdade, decidimos não incluir ex-professores.
} 
dos artigos indexados no SciELO e 1,44\% dos trabalhos indexados no ISI.

Em relação a trabalhos apresentados em eventos, a produção teve uma evolução significativa, principalmente nos anos de 1997 a 1999. Além deste tipo de pesquisa, também foram estudados outros tipos de pesquisas, orientações de trabalhos tutelados (teses e dissertações), além das relações com artigos publicados pelos grupos de pesquisas. Buscou-se sempre verificar se os trabalhos eram fundamentados pelas linhas de pesquisas de cada Programa de Pósgraduação (Quadro 1).

O estímulo à Pós-graduação, na PUC-Campinas, também pode ser constatado em tomadas de contato com a pesquisa, junto às instituições de fomento, estimulando a sobrevivência dos Programas descritos acima. A porcentagem de verbas externas de fomento recebidas é pequena, na forma de bolsas de estudos e auxílios a projetos docentes financiados pela Coordenação de Aperfeiçoamento de Pessoas de Nível Superior (Capes), Conselho Nacional de Desenvolvimento Científico e Tecnológico (CNPq) e Fundação de Amparo à Pesquisa do Estado de São Paulo (Fapesp).

O objetivo desta pesquisa foi, especificamente, analisar a produção científica de uma Universidade privada respeitada (PUC-Campinas), tendo como base as pesquisas realizadas pelo corpo docente dos programas de pós-graduação Stricto Sensu. Para tal, analisou-se a vinculação da produtividade dos docentes com as linhas de pesquisas, as orientações de teses e dissertações, e o desenvol- vimento de vínculos importantes a essa pesquisa, como tipo de pesquisa básica; pesquisa aplicada e desenvolvimento experimental, e produtividade; Revistas ISI, SciELO e outros periódicos científicos; e trabalhos apresentados em congressos.

\section{MÉTODOS}

Para investigar a produção científica dos docentes dos Programas de Pós-graduação Stricto Sensu da PUC-Campinas, resgatou-se uma listagem com os nomes dos professores que estavam vinculados aos programas no ano 2002; posteriormente, foi realizada uma análise dessa lista através dos Currículos Lattes e dos Diretórios de grupos de pesquisa, recorrendo-se às informações sobre suas atividades nos anos estudados.

Investigou-se toda a produção científica dos docentes no período de 1995 a 2002, e também suas atividades de orientação em dissertações e teses, tendo sempre em vista o vínculo dos docentes com a instituição.

Para levantamento dos dados, examinou-se individualmente, no Currículo Lattes, o histórico científico dos docentes no período estudado, posteriormente, estas informações foram transformadas em uma base de dados em Access, para seu diagnóstico. Nessa base de dados, as produções foram classificadas por tipos - Pesquisa Básica, Aplicada e Desenvolvimento Experimental (OCDE, 1975) tipologias. Em relação aos trabalhos publicados em periódicos,

Quadro 1. Programas de Pós-graduação credenciados e linhas de pesquisa da PUC-Campinas (2001).

\begin{tabular}{|c|c|}
\hline Pós-Graduação (stricto sensu) & Linhas de Pesquisa \\
\hline Biblioteconomia e Ciência da Informação (Mestrado) & $\begin{array}{l}\text { a) Gestão de Serviços de Informação; b) Produção e Disseminação da } \\
\text { Informação. }\end{array}$ \\
\hline Educação / Ensino Superior (Mestrado) & $\begin{array}{l}\text { a) Avaliação Institucional; b) Docência em Instituições de Ensino Superior; } \\
\text { c) Universidade e a Formação de Professores para o Ensino Fundamental } \\
\text { e Médio. }\end{array}$ \\
\hline Filosofia Social e Ética (Mestrado) & $\begin{array}{l}\text { a) O Utilitarismo e seus críticos; b) Ética fenomenológica e hermenêutica; } \\
\text { c) A crítica da sociedade contemporânea. }\end{array}$ \\
\hline $\begin{array}{l}\text { Psicologia Clínica, Escolar, Como Profissional e Ciência } \\
\text { (Mestrado/Doutorado) }\end{array}$ & $\begin{array}{l}\text { a) Formação, Ensino e Pesquisa; b) Desenvolvimento, Comportamento e } \\
\text { Funcionamento Mental; c) Fundamentos e Medidas da Avaliação } \\
\text { Psicológica; d) Prevenção e Intervenção Psicológica; e) Psicologia do } \\
\text { Ensino e da Aprendizagem. }\end{array}$ \\
\hline Urbanismo (Mestrado) & a) História do Pensamento Urbanístico; b) Gestão Urbana. \\
\hline
\end{tabular}

Fonte: PUC-Campinas (2002. Disponível no URL: http://www.puc-campinas.br). Acesso em 15/10/2001. 
foram classificados segundo as bases de conhecimento que os registraram, ISI e SciELO (SPINAK, 1998); quanto aos periódicos que não estavam contemplados nestas bases internacionais, foram denominados como "demais revistas". Este termo teve apenas a função de nomear uma categoria para as revistas não constantes daquelas bases de dados, sem supor qualquer sugestão sobre a qualidade das publicações.

Posteriormente, realizou-se uma análise sobre os grupos de pesquisa, seguindo a mesma técnica aplicada para as tipologias e utilizando outra base de dados em ambiente operacional Access. Este tipo de investigação priorizou a participação dos docentes da PUC nesses grupos, avaliando então a quantidade de grupos de pesquisa; o papel dos docentes da PUC-Campinas na liderança destes grupos; o número de docentes que participam dos grupos; a relação da pesquisa de cada grupo com as linhas de pesquisas dos docentes em questão.

Diante das informações armazenadas nas duas bases de dados (Access), foi idealizada a medição da ciência e suas ramificações, - em forma de linhas de pesquisas ou temáticas -, (VELHO, 1985), priorizando-se as necessidades da instituição universidade e seu propósito (TRINDADE, 1999), com principal foco na Pós-graduação (GOLDSCHMIDT, 1996), ciclo que toma a responsabilidade de produzir ciência, tanto no país como na instituição estudada.

Além de todas as informações resgatadas e dos recursos utilizados, também foram averiguados documentos e projetos da Pró-Reitoria de Pesquisa para contrastar com os dados dos Diretórios de grupo e do Currículo Lattes.

Um estudo dessa amplitude dentro de uma universidade se faz necessário, para que a instituição possa visualizar suas especialidades (ROUSSEAU, 1998), seus pontos fortes e fracos e suas ameaças e possíveis oportunidades de investigação.

\section{RESULTADOS E DISCUSSÃO}

A primeira análise desenvolvida enfocou os grupos de pesquisa dos Programas de Pósgraduação, destacando suas relações com as linhas de pesquisas a partir de 1995 até 2002, as avaliações individuais de cada Programa segundo informações dos Diretórios de Grupo, dos relatórios trienais da Capes e uma análise da produção científica dos docentes da PUC-Campinas, através de uma pesquisa no Currículo Lattes. Nesse contexto, foram verificadas as incidências dos artigos completos publicados em periódicos; das produções técnicas; dos trabalhos publicados na íntegra e dos resumos de eventos e congressos; ademais das dissertações e teses orientadas pelo corpo docente.

Para o elencamento das atividades acadêmicas, fez-se o levantamento de todas as disciplinas ministradas pelo corpo docente (1995 a 2002); juntaram-se a estas informações as atividades com as orientações e com os grupos de pesquisa, procurando analisar se existe dentro dos Programas de Pós-graduação Stricto Sensu um entendimento de conduta correta ao orientar os discentes.

A análise dos grupos de estudo incluiu a quantidade de equipes (grupos) existentes em cada ano, a liderança de pesquisadores/docentes da PUC-Campinas no grupo de pesquisa, a quantidade de docentes da PUC-Campinas participantes nos grupos e a relevância do grupo de pesquisa frente às linhas de pesquisa existentes em cada Programa de Pós-graduação (Tabela 1).

Para o entendimento da Tabela 1 é recomendável visualizar as linhas de pesquisa existentes em cada Programa de Pós-graduação no Quadro 1 (Programas de Pós-graduação Credenciados e Linhas de Pesquisa), exceto para o item (N), que especifica a não existência de relação do grupo de pesquisa com as linhas existentes nos Programas.

Nos anos de 1995 e 1999 não foi cadastrado nenhum grupo de pesquisa, em virtude do CNPq não estar cadastrando os grupos nessas datas; mesmo assim, as atividades dos grupos de pesquisa ainda eram vistas como proposta de difusão do conhecimento dentro da Instituição.

Em 1996, foi diagnosticado um grupo de pesquisa existente junto ao Programa de Psicologia, formado por um único participante ${ }^{4}$, que também era o líder, e cuja linha de pesquisa era Prevenção e Intervenção Psicológica.

\footnotetext{
${ }^{4}$ Curiosamente alguns Grupos de Pesquisa continham somente um investigador Doutor da instituição e como parte da equipe eram contemplados por alunos de Pós-graduação e alunos de iniciação científica. Esclarecendo que esta particularidade foi diagnosticada no período estudado, não respondemos por períodos anteriores e posteriores a esta investigação.
} 
Tabela 1. Grupo de Pesquisa segundo a quantidade de participantes, liderança e enlace com as linhas de pesquisa.

\begin{tabular}{|c|c|c|c|c|c|c|c|c|c|c|c|c|c|c|c|c|c|c|c|c|}
\hline \multirow{2}{*}{ Ano } & \multicolumn{4}{|c|}{ Biblioteconomia $(\mathrm{Cl})$} & \multicolumn{4}{|c|}{ Educação } & \multicolumn{4}{|c|}{ Filosofia } & \multicolumn{4}{|c|}{ Psicologia } & \multicolumn{4}{|c|}{ Urbanismo } \\
\hline & $\mathrm{Q}$ & $\mathrm{L}$ & $\mathrm{P}$ & $\wedge$ & Q & $\mathrm{L}$ & $\mathrm{P}$ & $\wedge$ & $\mathrm{Q}$ & $\mathrm{L}$ & $\mathrm{P}$ & $\wedge$ & Q & $\mathrm{L}$ & $\mathrm{P}$ & $\wedge$ & $\mathrm{Q}$ & $\mathrm{L}$ & $\mathrm{P}$ & $\hat{\wedge}$ \\
\hline \multicolumn{21}{|l|}{1995} \\
\hline 1996 & & & & & & & & & & & & & 1 & 1 & 1 & D & & & & \\
\hline 1997 & & & & & 1 & 1 & 3 & B & & & & & & & & & & & & \\
\hline 1998 & 1 & 1 & 1 & A & 3 & 3 & 9 & $\mathrm{C} / \mathrm{A} / \mathrm{B}$ & & & & & & & & & & & & \\
\hline 1999 & & & & & & & & & & & & & & & & & & & & \\
\hline 2000 & 1 & 1 & 1 & B & & & & & 1 & 1 & & C & 1 & 1 & 1 & $\mathrm{~N}$ & 1 & 1 & 1 & B \\
\hline 2001 & & & & & 1 & 1 & 3 & B & & & & & & & & & & & & \\
\hline 2002 & & & & & 3 & 4 & 5 & $\mathrm{~N} / \mathrm{C} / \mathrm{C}$ & 3 & 3 & 5 & $\mathrm{~B} / \mathrm{A} / \mathrm{A}$ & 5 & 5 & 7 & $\mathrm{~A} / \mathrm{A} / \mathrm{A} / \mathrm{B} / \mathrm{D}$ & 3 & 4 & 7 & $\mathrm{~B} / \mathrm{B} / \mathrm{A}$ \\
\hline Total & 2 & 2 & 2 & - & 8 & 8 & 20 & - & 4 & 4 & 5 & - & 7 & 7 & 9 & - & 4 & 5 & 8 & - \\
\hline
\end{tabular}

Fonte: CNPq, 2003 (Currículo Lattes), Dados trabalhados pelo autor.

Notas: $\mathrm{Q}=$ Quantidade de Grupos de Pesquisa Certificados no Ano;

$\mathrm{L}$ = Líderes do Grupo de Pesquisa que fazem parte dos Programas de Pós-graduação da PUC-Campinas;

$\mathrm{P}=$ Quantidade de participantes da PUC-Campinas no Grupo de Pesquisa;

$\wedge$ = Linha de Pesquisa dos Programas de Pós-graduação da PUC-Campinas.

O ano de 1997 teve somente um grupo de pesquisa existente, semelhante ao ano anterior, sendo formado por três participantes docentes da instituição PUC-Campinas, cujo líder era um dos participantes, enquanto os outros eram pós-graduandos. Sua linha de pesquisa era Docência em Instituições de Ensino Superior.

No ano de 1998, a incidência de formalização de grupos de pesquisa começa a ganhar espaço dentro da PUC-Campinas, trazendo alunos da graduação a participarem de estudos. Em alguns programas, começa-se a Iniciação Científica e agregação de profissionais da área ao universo dos grupos de pesquisa. Neste ano, surgem quatro grupos de pesquisa, sendo um em Ciência da Informação (com um líder, um participante docente, alunos de graduação e mestrandos como suporte técnico, além de outros profissionais da área); a linha de pesquisa deste grupo era focada em Gestão de Serviços de Informação. Os outros três grupos, em Educação, apresentavam um líder em cada grupo; tinham um total de nove docentes participantes na soma de todos os grupos e eram categorizados cada um em uma linha de pesquisa diferente, como segue: Avaliação Institucional; Docência em Instituições de Ensino Superior; Universidade e a Formação de Professores para o Ensino Fundamental e Médio.

No período de 2000 a 2002 a concepção de grupo de pesquisa nos programas de pós-graduação passa a ser vital para a avaliação da instituição pela Capes. A PUC-Campinas, acreditando que a transmissão do conhecimento não pode ser dissociada de seu processo de construção, valoriza a integração transmissão/produção do conhecimento que permite a visão crítica, contextualizada e relativizada da informação, adotando métodos e procedimentos característicos da sociedade técnico-científica atual, a fim de formar profissionais mais cons-cientes, criativos e eficientes (CAMARGO, 2002, p. 3). Desde essa perspectiva, valoriza-se o papel participativo dos grupos de pesquisa, atribuindo-lhe importância integrativa na produção e transmissão de conhecimentos, juntamente com o consenso maior, a Universidade, enquanto espaço de formação e reflexão crítica sobre os rumos da sociedade e particularmente da visão de mundo, conhecimentos e técnicas.

Nestes anos (2000 a 2002), são certificados 19 grupos de pesquisas, os quais, no ano de 2000, distribuíram-se da seguinte forma: um grupo em Ciência da Informação (com um líder, um participante docente, alunos de graduação e mestrandos como suporte técnico), tendo como enfoque na linha de pesquisa a Produção e Disseminação da Informação; um grupo em Filosofia (com um líder, um participante docente, alunos de pós-graduação como suporte técnico), enfocando, na linha de pesquisa, a A Crítica da Sociedade Contemporânea; um grupo em Psicologia (com um líder, um participante docente, alunos de pós-graduação e profissionais como 
suporte técnico), com uma linha de pesquisa, entretanto, não condizente com as enfocadas no programa de pós-graduação respectivo); um grupo em Urbanismo e Arquitetura (com um líder, um participante docente, alunos de graduação e mestrandos como suporte técnico), cuja linha de pesquisa contemplava a História do Pensamento Urbanístico.

No ano de 2001, apenas um grupo, em Educação (com um líder, três docentes participantes, alunos de graduação e mestrandos como suporte técnico), cuja linha de pesquisa enfocava a Docência em Instituições de Ensino Superior. Em 2002, os grupos distribuíram-se desta forma: três grupos em Educação (com um total de quatro líderes, sendo um grupo com dois lideres da casa, cinco docentes participantes, alunos de graduação e mestrandos como suporte técnico) as linhas de pesquisa de dois desses grupos enfocavam a Universidade e a Formação de Professores para o Ensino Fundamental e Médio, enquanto um dos três grupos não apresentou linha de pesquisa condizente com o respectivo programa; , três grupos em Filosofia (com um total de seis líderes, tendo cada grupo dois líderes da casa, seis docentes participantes, alunos de graduação e mestrandos como suporte técnico), desses três grupos, dois enfocavam suas linhas de pesquisa em $\mathrm{O}$ Utilitarismo e seus Críticos, enquanto o outro grupo contemplava a Ética Fenomenológica e Herme- nêutica; houve cinco grupos em Psicologia (com cinco líderes, sete docentes participantes, alunos de graduação e mestrado como suporte técnico) cujas linhas de pesquisa enfocavam Formação, Ensino e Pesquisa - três grupos -, Desenvolvimento, Comportamento e Funcionamento Mental - um grupo - e Prevenção e Intervenção Psicológica - um grupo; outros três grupos em Psicologia (com quatro líderes, um grupo tendo líderes da casa, sete docentes participantes, alunos de graduação e mestrandos como suporte técnico), cujas linhas de pesquisa enfocavam Gestão Urbana - dois grupos - e História do Pensamento Urbanístico - um grupo.

Em relação a artigos publicados por docentes da PUC-Campinas, analisamos a sua distribuição em veículos indexados nacional e internacionalmente (ISI, SciELO e publicações não indexadas) (Figura 1).

A média de publicações em geral é modesta, principalmente em relação à publicação em revistas indexadas no ISI e revistas indexadas no SciELO (Base de Dados da produção científica da América Latina e Caribe).

Outro dado são os veículos de publicações dos docentes da PUC-Campinas: o Programa de Urbanismo publicou principalmente na sua revista Óculum, tendo também um artigo indexado no SciElO (São Paulo em Perspectiva) e um artigo

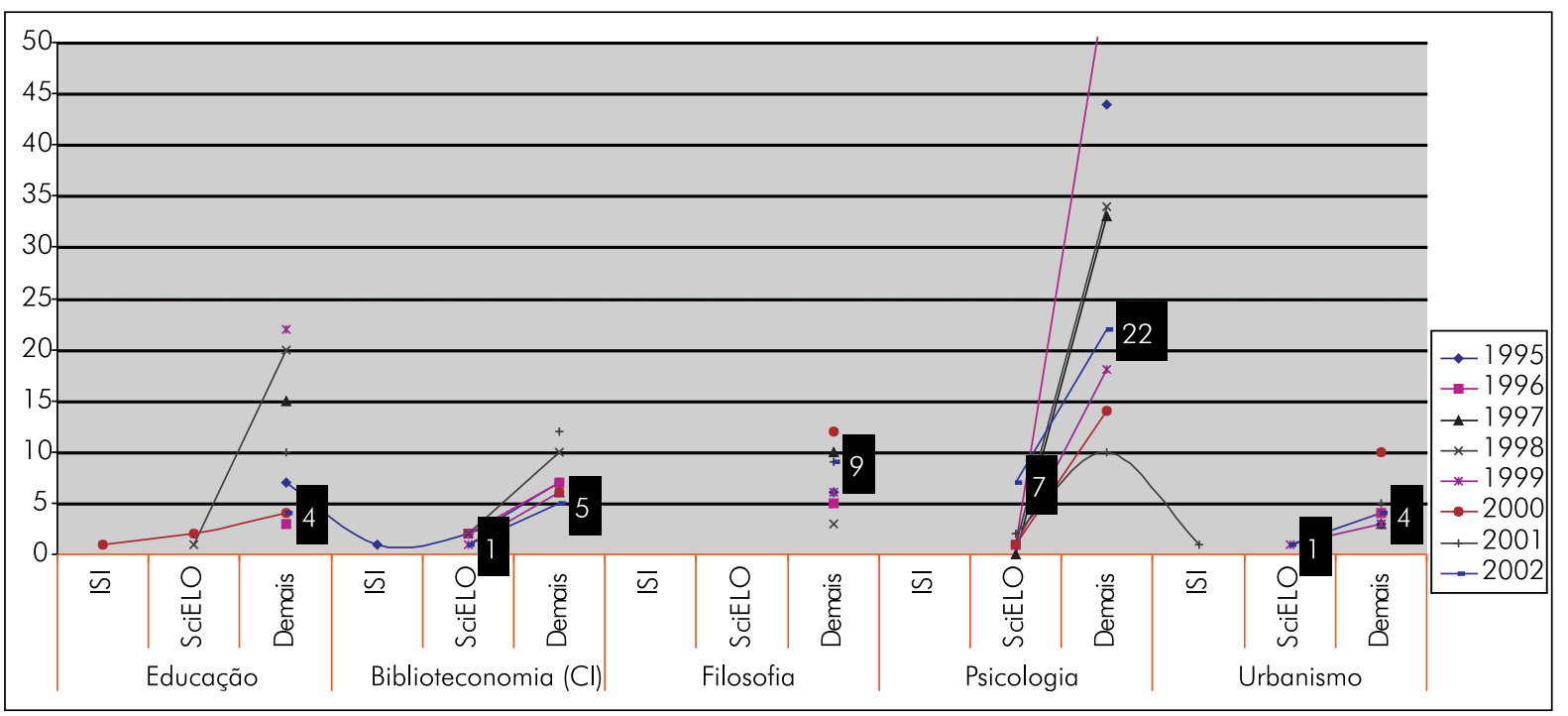

Figura 1. Produção Científica por Programa: Indexação dos trabalhos na ISI, SciELO e nas demais vias de publicação. Fonte: CNPq (Currículo Lattes). Dados trabalhados pelo autor. 
indexado no ISI (Geoforum); os docentes do Programa de Biblioteconomia utilizam, principalmente, as revistas Transinformação (Revista do Programa), Datagramazero (on-line), Informação e Perspectiva e Revista de Bibliote-conomia de Brasília como vias de publicação, tendo também oito artigos indexados no SciELO (São Paulo em Perspectiva e Ciência da Informação) e um artigo indexado no ISI (Scientometrics); no Programa de Psicologia, o mais produtivo da Instituição, os docentes utilizaram as revistas Psicologia Escolar e Educacional, Revista Grupo SPAG, Revista daAssociação Brasileira de Psicoterapia Analítica de Grupo, Transinformação e Boletim de Psicologia como as principais vias de publicação, tendo também 13 artigos indexados no SciELO (Psicologia: Reflexão e Critica, Psicologia: Teoria e Pesquisa, Revista da Faculdade de Educação USP, Arquivo Neuro-Psiquiatria); no Programa de Filosofia, os docentes utilizaram a Revista Brasileira de Filosofia, Revista Jurídica, Reflexão (Revista do Programa), Cadernos de Teologia, Revista Sial-Servizio Informazione America Latina, e Ethica, como as principais vias de publicação, não tendo nenhum trabalho publicado nas revistas indexadas pelo ISI e SciELO; quanto ao Programa de Educação, seus docentes utilizaram as revistas Série Acadêmica e Revista de Educação (Revista do Programa) como as principais vias de publicação, tendo também três artigos indexados no SciELO (Cadernos CEDES e Revista Latinoamericana de Enfermagem) e um artigo indexado no ISI (Educational Psychology Review).

No período estudado (1995-2002), a média de publicações dos docentes, examinada em relação à produção individual (visualizada em quadro abaixo), revelou que, somente 15 dos 17 docentes do Programa de Educação publicaram; todos os 15 docentes do Programa de Psicologia, publicaram no período; tanto no Programa de Urbanismo como no Programa de Educação, 3 dos seus respectivos 10 docentes não publicaram um artigo sequer no período. Os Programas de Biblioteconomia (6 docentes) e o Programa de Filosofia (8 docentes), mantiveram-se em dia com as publicações, tendo todos os docentes publicado no período estudado.

Em todo o período, a produção institucional de docentes da pós-graduação totalizou 451 artigos publicados em periódicos nacionais, estando 5,76\% desses artigos indexados no SciELO; de um universo de 48 artigos publicados em revistas internacionais, somente três (1,44\%) trabalhos estão indexados no ISI.

A média de publicação docente/ano é de um artigo apenas, publicado ou não em veículos internacionalmente indexados. Um critério imposto pelo diretório da Capes para as áreas em discussão, têm a recomendação de pelo menos dois trabalhos publicados em cada ano, sendo aceito artigos, livros e trabalhos apresentados em eventos pelo corpo docente. APUC-Campinas, no geral, conseguiu atingir uma maturidade neste ponto.

Dentro da análise artigo/ano, foi detectada uma discrepância interessante: enquanto alguns docentes publicaram menos que um artigo por ano, outros docentes atingiram um número acima da média; entretanto, como o enfoque desta pesquisa não era analisar os participantes individualmente, a observação deste fato serve apenas para informar que, na Instituição PUC-Campinas, existem docentes acima da média, embora existam também outros bem abaixo da média, em relação a publicar suas pesquisas.

Um dos critérios da Capes para a área de Educação, é que não exige publicar-se em revistas internacionais, mas sim, que haja uma constante média de publicações por parte dos Programas na área; entretanto, para a área de Ciência da Informação (Biblioteconomia), a Capes recomenda que as publicações sejam feitas em revistas internacionalmente indexadas ou que façam parte das publicações Qualis-Brasil, as quais servem de parâmetros para a avaliação da instituição executada pela Capes.

Foi árduo relacionar as linhas de pesquisa existentes em cada Programa de Pós-graduação com as produções dos respectivos docentes, pois essa tarefa exigiu a análise dos resumos e palavras-chave de cada artigo, ou seja, examinar cada uma das produções e extrair a sua essência temática, para então proceder-se à sua comparação com as linhas de pesquisa existentes nos respectivos programas (Figura 2).

Em relação aos seus indicadores, o autor sugere que seja consultada a Tabela 1 para compreender-se o significado das siglas ( $a, b, c, d$, e de cada programa de pós-graduação), referentes às nomenclaturas das linhas de pesquisa. 


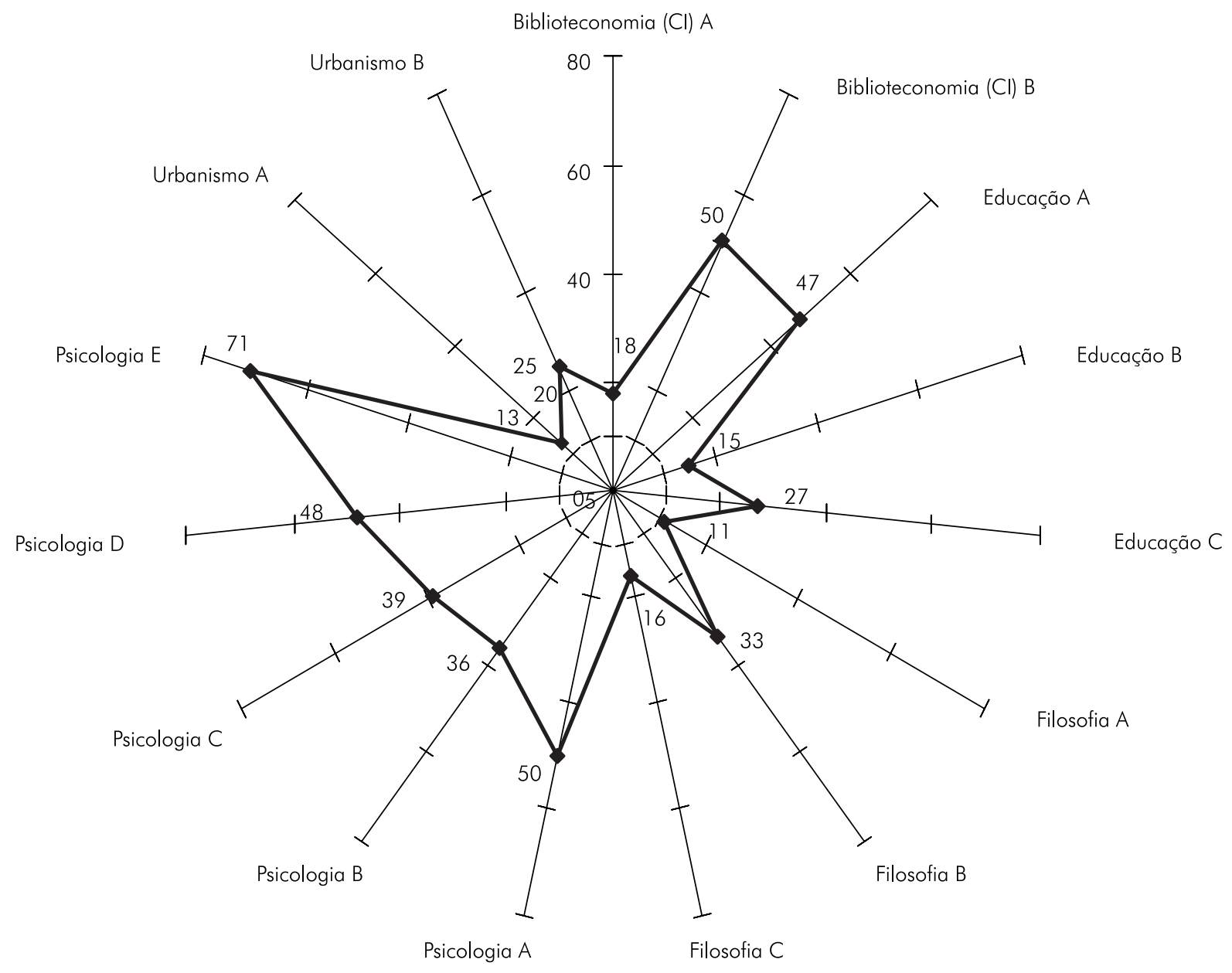

Figura 2. Produção científica em artigos relacionada às linhas de pesquisas dos Programas de Pós-graduação Stricto Sensu da PUC-Campinas: período de 1995 a 2002. Fonte: CNPq (Currículo Lattes). Dados trabalhados pelo autor.

O Programa de Biblioteconomia gerou quase toda a sua produção científica em torno da linha de pesquisa Produção e Disseminação da Informação (50 artigos), por conter maior número de professores nesta linha (4 docentes), enquanto a outra linha de pesquisa, Gestão de Serviços da Informação, gerou 18 trabalhos (por 2 docentes) no período estudado. De 1995 a 2002, este programa, sofreu uma forte reestruturação do seu corpo docente, momento em que infelizmente a linha de gestão perdeu três docentes de peso na produção científica nacional e teve a transferência de um docente (linha de Produção e Disseminação da Informação) para o Programa de Psicologia.

Em Educação, com seu programa estruturado em três linhas de pesquisa, consolidaram-se os seguintes dados: linha (a), 47 trabalhos publicados; linha (b), 15 trabalhos publicados; linha (c), 27 trabalhos publicados. No Programa de Educação, a linha de pesquisa de destaque é a Avaliação Institucional, com a produção científica do Programa voltada para a avaliação dos cursos Às vertentes desta, atrelam-se as demais linhas de pesquisa; portanto, mesmo docentes que, prioritariamente, não seguem esta linha de pesquisa, também publicam nela, pela abrangência mesma desta linha.

Em Filosofia, a produção científica priorizou como linha de pesquisa, a área da ética, (Ética fenomenológica e hermenêutica - 33 trabalhos), tendo um número reduzido de trabalhos publicados nas demais linhas: a linha (a) desenvolveu um total de 11 trabalhos, enquanto a linha (c) desenvolveu 16 trabalhos no período estudado. 
O Programa de Arquitetura e Urbanismo, formado e constituído em 1999, ainda encontra muitas dificuldades para consolidar sua produção científica. Este programa é o que tem a menor produção, sendo que cinco dos dez docentes do programa obtiveram a titulação máxima entre os anos de 1999 e 2002, ou seja, as atividades dos docentes no programa só podem ser cobradas da metade do quadro efetivo. Mesmo com uma série de justificativas a seu favor, a produção científica do programa ainda é modesta, tendo 13 trabalhos publicados na linha de pesquisa (a) e 25 trabalhos na linha de pesquisa (b).

A análise realizada frente à produção de artigos completos, classifica-os em trabalhos publicados com um autor, com dois autores, três, ou com quatro ou mais (até oito) autores participantes (Tabela 2).

A produção científica institucional se faz presente em grande escala com as produções de autor único, com exceção feita à produção em Psicologia em 2002, quando predominou a dupla autoria, e em que houve um ressalto interessante: das 10 publicações, somente 2 foram trabalhadas dentro do programa, realizadas em parceria com outro docente do programa.

Quase não houve produção em conjunto pelos docentes dos programas da instituição. Essa pouca produção em parceria numerosa, explica-se pelo fato de que a maioria dos grupos de pesquisa conta com apenas um docente doutor; outro aspecto a notar é estar cada grupo de pesquisa trabalhando com um número máximo de quatro docentes, o que explica a produção científica ter, geralmente, no máximo quatro autores-participantes.

Alguns cursos como Psicologia, Filosofia e Educação geralmente publicam suas experiências em livro e capítulos de livro, mesmo sabendo que este veículo não gera impacto; entretanto, a publicação em livros é uma característica da área de Ciências Humanas, considerando-se o livro como um forte componente na disseminação do conhecimento.

Analisando a produção em congressos, colóquios, seminários e encontros, nota-se uma participação considerável dos docentes da universidade estudada. Este tópico faz parte da reestruturação política de incentivo à produção científica institucional, reestruturação propiciadora de novos artigos científicos, pois, geralmente, um trabalho (artigo) origina-se e começa a ser executado na forma de apresentação em eventos; depois desta primeira etapa é realizado um trabalho de crítica externa frente à proposta e somente no terceiro estágio é que o autor pode colher as críticas e modelar o trabalho para transformá-lo em artigo científico (ZANOTTO, 1999).

O Programa de Pós-graduação em Psicologia é o mais eficiente em publicar trabalhos em eventos científicos nacionais e internacionais, seguido pelos Programas em Educação, Biblioteconomia e Ciência da Informação, Urbanismo e Filosofia (Tabela 3).

Um dado interessante em relação a trabalhos apresentados em eventos, é que muitos deles foram selecionados para os principais eventos de cada área,

Tabela 2. Artigos completos por quantidade de autorias.

\begin{tabular}{|c|c|c|c|c|c|c|c|c|c|c|c|c|c|c|c|c|c|c|c|c|}
\hline \multirow{2}{*}{ Ano } & \multicolumn{4}{|c|}{ Biblioteconomia $(\mathrm{Cl})$} & \multicolumn{4}{|c|}{ Educação } & \multicolumn{4}{|c|}{ Filosofia } & \multicolumn{4}{|c|}{ Psicologia } & \multicolumn{4}{|c|}{ Urbanismo } \\
\hline & 1 & 2 & 3 & $>4$ & 1 & 2 & 3 & $>4$ & 1 & 2 & 3 & $>4$ & 1 & 2 & 3 & $>4$ & 1 & 2 & 3 & $>4$ \\
\hline 1995 & 8 & 1 & 1 & - & 5 & 1 & - & - & 6 & - & - & - & 31 & 4 & 1 & - & 3 & - & - & - \\
\hline 1996 & 4 & 3 & 1 & 1 & 2 & - & - & - & 5 & - & - & - & 36 & 7 & 3 & 1 & 4 & 1 & - & - \\
\hline 1997 & 6 & - & - & - & 13 & 1 & 1 & - & 9 & 1 & - & - & 25 & 3 & 1 & 2 & 2 & 1 & - & - \\
\hline 1998 & 7 & 1 & 3 & - & 20 & - & - & - & 3 & - & - & - & 22 & 2 & 1 & 2 & 3 & - & - & - \\
\hline 1999 & 2 & - & 1 & 2 & 18 & 2 & 1 & 1 & 7 & - & - & - & 15 & 1 & - & - & 4 & - & - & - \\
\hline 2000 & 6 & 1 & - & - & 7 & 1 & - & - & 9 & 3 & - & - & 10 & 3 & - & - & 9 & - & - & - \\
\hline 2001 & 7 & 5 & 1 & - & 3 & 1 & 3 & 3 & 8 & - & - & - & 10 & 1 & - & - & 5 & 1 & - & - \\
\hline 2002 & 2 & 3 & 1 & - & 3 & - & 1 & - & 8 & 1 & - & - & 7 & 10 & 3 & 3 & 7 & 2 & - & - \\
\hline Total & 42 & 14 & 8 & 3 & 71 & 6 & 6 & 4 & 55 & 5 & - & - & 156 & 31 & 9 & 8 & 37 & 5 & - & - \\
\hline
\end{tabular}

Fonte: CNPq (2003) (Currículo Lattes). Dados trabalhados pelo autor.

Notas: 1 = Um Autor; 2 = Autoria com dois participantes; $3=$ Autoria com três participantes; $>4=$ Autoria com quatro ou mais participantes. 
Tabela 3. Trabalhos completos e resumos apresentados em eventos.

\begin{tabular}{|c|c|c|c|c|c|c|c|c|c|c|c|c|c|c|c|c|c|c|c|c|}
\hline \multirow{2}{*}{ Ano } & \multicolumn{4}{|c|}{ Biblioteconomia $(\mathrm{Cl})$} & \multicolumn{4}{|c|}{ Educação } & \multicolumn{4}{|c|}{ Filosofia } & \multicolumn{4}{|c|}{ Psicologia } & \multicolumn{4}{|c|}{ Urbanismo } \\
\hline & $\mathrm{N}$ & $\mathrm{R}$ & 1 & $\mathrm{~S}$ & $\mathrm{~N}$ & $\mathrm{R}$ & I & $\mathrm{S}$ & $\mathrm{N}$ & $\mathrm{R}$ & I & $\mathrm{S}$ & $\mathrm{N}$ & $\mathrm{R}$ & I & $\mathrm{S}$ & $\mathrm{N}$ & $\mathrm{R}$ & I & $\mathrm{S}$ \\
\hline 1995 & 5 & 5 & 1 & - & 3 & 9 & - & - & 3 & 2 & - & 1 & 8 & 28 & - & 4 & 1 & 2 & - & - \\
\hline 1996 & 5 & 1 & 1 & - & 1 & 3 & - & 1 & 6 & 1 & 1 & 2 & 21 & 31 & - & 12 & 2 & 1 & - & 1 \\
\hline 1997 & 4 & 6 & - & - & 6 & 11 & - & 4 & 1 & 1 & - & - & 29 & 36 & 5 & 10 & 5 & - & - & - \\
\hline 1998 & 3 & 1 & 4 & - & 15 & 19 & 1 & 3 & - & 1 & 1 & 3 & 8 & 47 & 12 & 6 & 6 & 2 & - & 1 \\
\hline 1999 & 3 & 3 & 1 & - & 1 & 4 & 2 & 3 & - & 1 & 1 & - & 21 & 38 & 1 & 5 & 1 & - & 1 & - \\
\hline 2000 & 11 & 2 & 3 & - & 11 & 5 & 2 & 3 & - & 1 & 2 & 2 & 21 & 29 & 3 & 6 & 8 & - & 1 & - \\
\hline 2001 & 9 & 4 & - & - & 9 & 2 & - & 1 & 7 & - & 3 & 1 & 17 & 27 & 1 & 1 & 1 & - & 2 & - \\
\hline 2002 & 9 & 9 & 2 & - & 5 & 3 & - & - & 2 & 1 & 1 & - & 12 & 39 & 2 & 9 & 4 & - & - & - \\
\hline Total & 49 & 31 & 12 & - & 51 & 56 & 5 & 15 & 19 & 8 & 9 & 9 & 137 & 275 & 24 & 53 & 28 & 5 & 4 & 2 \\
\hline
\end{tabular}

Fonte: CNPq (2003) (Currículo Lattes). Dados trabalhados pelo autor.

Notas: N = Evento e/ou Encontro Nacional; R = Resumo em Evento e/ou Encontro Nacional; I = Evento e/ou Encontro Internacional; $\mathrm{S}=$ Resumo em Evento e/ou Encontro Internacional.

tendo também uma forte relação com os grupos de pesquisa, seguindo recomendações da Capes.

Outro recorte estudado nesta pesquisa resultou da análise entre artigos publicados em revistas e trabalhos apresentados em eventos, e sua relação direta com os grupos de pesquisa.

As informações referentes a artigos completos, publicados em revistas, que têm relação direta com os grupos de pesquisa, distribuem-se assim: 19\% no Programa de Biblioteconomia e Ciência da Informação; 75\% no Programa de Educação; 72\% no Programa de Filosofia; 38\% no Programa de Psicologia e 58\% no Programa de Urbanismo.

Quanto à porcentagem dos trabalhos apresentados em eventos relacionados com os grupos de pesquisa, a sua distribuição é a seguinte: em Biblioteconomia, 23\% dos trabalhos apresentados estão relacionados aos grupos de pesquisa; esses traballhos são 48\% no Programa de Educação; $89 \%$ no Programa de Filosofia; 65\% no Programa de Psicologia e 50\% no Programa de Urbanismo.

Outra questão é a relação das orientações das teses e dissertações, defendidas no período de 1995 a 2002, com as linhas de pesquisa de cada programa de pós-graduação Stricto Sensu. A sua distribuição se faz da seguinte forma:

Todas as orientações estudadas foram realizadas sobre os docentes que ainda compõem o quadro funcional de cada programa, não se incluindo os docentes que deixaram a instituição no período estudado (fato comprovado pelo Programa de Biblioteconomia e Ciência da Informação, segundo informações da Capes - ficha de avaliação do triênio, 2001/2003) (Figura 3).

Cada programa, com sua particularidade, atingiu um número significativo em relação à média orientação/ano; o Mestrado em Biblioteconomia (1,54 orientação por docente/ano) atingiu os resultados esperados pelo autor, enquanto o Mestrado em Arquitetura e Urbanismo, programa teve seu inicio em 1999, conseguiu resultado acima do esperado (1,93 orientação por docente/ano), pois, com as primeiras defesas de tese apresentadas em 2001, atingiu um total de 31 dissertações defendidas entre os anos de 2001 e 2002; já o Programa de Biblioteconomia distinguiu-se com um total de 74 dissertações defendidas no período de 1995 a 2002.

O número de orientações defendidas por linha de pesquisa no Programa de Biblioteconomia, foi de 35 orientações para linha (a) e 39 orientações para linha (b); quanto ao Programa de Arquitetura e Urbanismo, o número foi de 14 orientações para a linha de pesquisa (a) e 17 orientações para a linha de pesquisa(b).

As orientações efetuadas pelos docentes dos Programas (Mestrado e Doutorado) em Psicologia atingiram uma média muito elevada em relação às dos demais Programas (2,71 orientação por docente/ ano), e um percentual muito superior ao de outras instituições que contemplam Mestrado e Doutorado na área. 


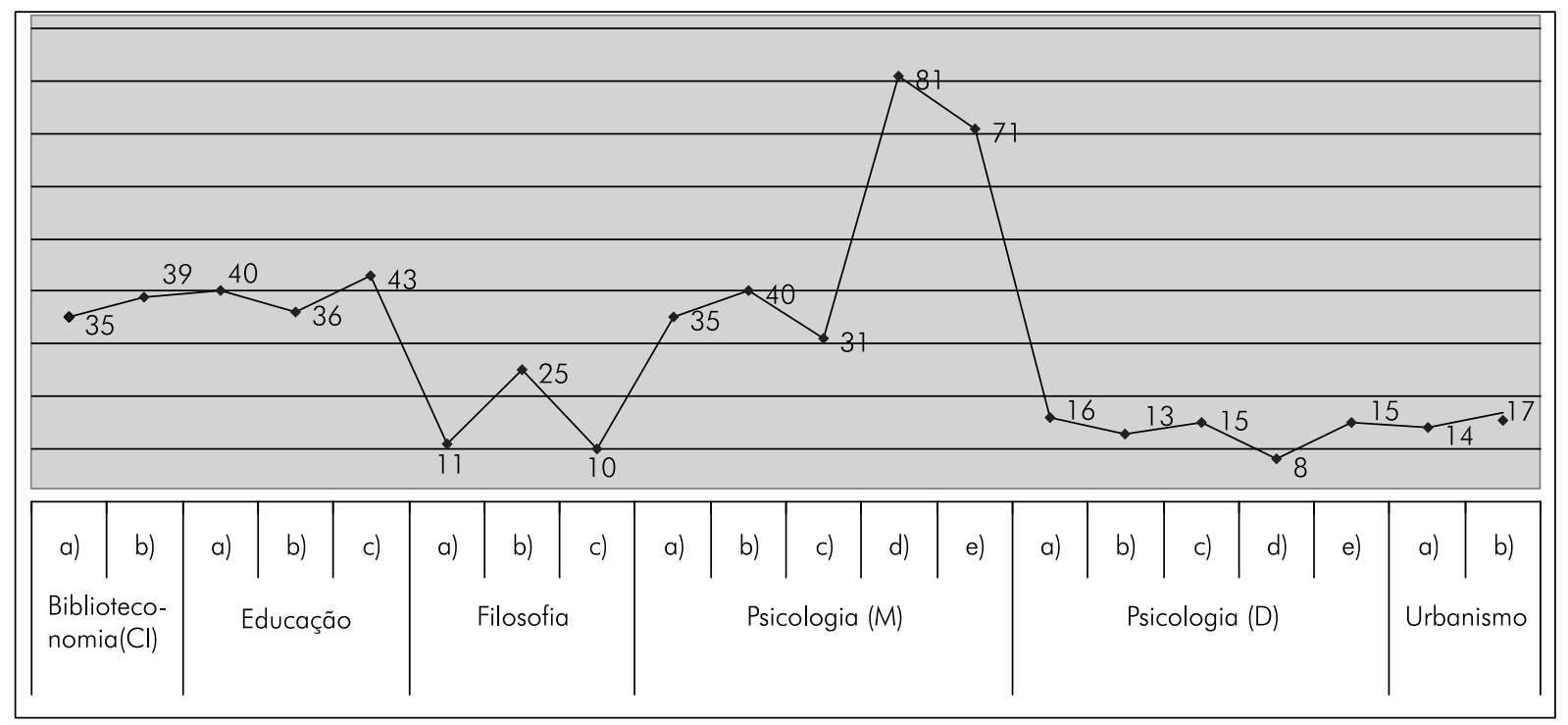

Figura 3. Orientações das teses e dissertações relacionadas às linhas de pesquisas dos programas de pós-graduação Stricto Sensu da PUC-Campinas: período de 1995 a 2002.

Fonte: CNPq (Currículo Lattes). Dados trabalhados pelo autor.

Os resultados da Psicologia descrevem-se da seguinte forma: no Mestrado, a linha de pesquisa (a) teve 35 orientações; linha de pesquisa (b), 40 orientações; linha de pesquisa (c) 31 orientações; linha de pesquisa (d) 81 orientações; linha de pesquisa (e) 71 orientações. No Doutorado, a distribuição se fez da forma seguinte: 16 trabalhos orientados na linha de pesquisa (a); 13 trabalhos orientados na linha de pesquisa (b); 15 trabalhos orientados na linha de pesquisa (c); 8 trabalhos orientados na linha de pesquisa (d) e 15 trabalhos orientados na linha de pesquisa (e). Este Programa de Doutorado, constituído em 1999, teve as primeiras teses defendidas em 2001, apresentando uma cifra acima do esperado num curto período de tempo: 67 teses orientadas e defendidas.

A média de orientação por docentes do Programa de Educação é de 0,88 orientações por docente/ano, distribuindo-se em 40 trabalhos orientados na linha de pesquisa (a); 36 trabalhos orientados na linha de pesquisa (b) e 43 trabalhos orientados da linha de pesquisa (c). O Programa de Filosofia teve uma média de 0,71 orientações por docente, distribuídas em 11 trabalhos orientados na linha de pesquisa (a); 25 trabalhos orientados na linha de pesquisa (b) e 10 trabalhos orientados da linha de pesquisa (c). Ambos os Programas tiveram uma média abaixo do esperado pelo pesquisador.
Tendo em vista a função acadêmica dos docentes, na dissertação que originou este trabalho, analisaram-se as disciplinas ministradas nos programas, com o propósito de verificar a adequação e abrangência da sua estrutura curricular em relação às linhas de pesquisa dos docentes.

Para o Programa de Biblioteconomia e Ciência da Informação, as linhas de pesquisa sofreram uma ligeira modificação; pois, até 1999, as disciplinas eram definidas em torno das linhas Administração de Serviços de Biblioteca, Arquivos e Informação; Informação para Indústria e Negócios; Planejamento e Administração de Programas de Leitura - todos voltados para a área de concentração em Planejamento e Administração de Sistemas de Informação. Em 2001, a proposta de passar para a área de concentração em Administração da Informação foi implementada, pois muito se produzia na linha de pesquisa Produção e Disseminação da Informação, enquanto que, com as linhas existentes até 2000 , não existia espaço para enfatizar-se a produção nesta linha.

De modo geral, segundo os resultados da análise referente aos objetivos, os docentes do Programa de Psicologia indiscutivelmente são os que mais produziram na instituição, em todos os quesitos. Este modelo de produção em série deve ser seguido pelos demais Programas. 
Além dos pontos discutidos acima, outro elemento importante para analisar a pesquisa na instituição foi o dos vínculos estabelecidos (Relação da Produção Científica com os Grupos de Pesquisa; Tipo de Pesquisa; Veiculação da Produção Científica e Produtividade Científica); para essa análise, o enfoque e a preocupação centraram-se em cada programa de pós-graduação (Biblioteconomia; Educação; Psicologia; Filosofia; Arquitetura e Urbanismo), relacionando a produção individual dos docentes à área de conhecimento de cada programa e de seus grupos de pesquisa consolidados.

Observou-se que os Programas de Pós-graduação em Psicologia e Educação são os únicos que possuem grupos de pesquisa não atrelados às linhas de pesquisa existentes na PUC-Campinas; entretanto, as relações da produção científica/docente, com os grupos de pesquisa e com as respectivas linhas de pesquisa existentes nos programas citados acima, estão distribuídas de maneira corretamente bem elevada. Nos demais programas, os grupos apresentam perfis muito distintos. Em Biblioteconomia, com dois grupos, um em cada linha de pesquisa, desfizeram-se os grupos que não tinham relação direta com o Programa (como era o caso nos anos de 1995 a 1998, em que o Programa tinha 7 grupos dispersos). O Programa de Filosofia consolidou de forma coerente suas linhas de pesquisas; porém, seus projetos, nem sempre se inseriram adequadamente: a linha A Crítica da Sociedade Contemporânea, por exemplo, incluiu um projeto sobre Política do Cotidiano (de 1998 a 2000), que não foi considerado adequado, por ter uma formulação vaga, segundo a Capes. O Programa em Urbanismo e Arquitetura possui quatro grupos de pesquisa consolidados, sendo estes bem distribuídos entre as duas linhas de pesquisa existentes.

Em todos os Programas (Educação; Biblioteconomia; Filosofia; Psicologia e Urbanismo) procurou-se estudar e classificar o foco mais evidente no tipo da pesquisa desenvolvida; para tanto, estipulou-se chamar esses tipos de Pesquisa Básica, Pesquisa Aplicada e Desenvolvimento Experimental (Figura 4).

APUC-Campinas e seus programas de pósgraduação são norteados pela pesquisa básica, como qualquer outra instituição de ensino, pois a pesquisa básica é o aprimoramento na busca do conhecimento, estruturando as propriedades e as conexões com vistas à formulação de hipóteses, teorias e leis (OCDE, 1975). Contudo, em todos os Programas estudados, a pesquisa básica caracterizou-se fundamentalmente pela orientação às pesquisas, sendo estas definidas como pesquisas básicas orientadas; o que explica o grande percentual neste tipo de pesquisa. Em seguida, observou-se a pesquisa aplicada, cujos resultados foram fundamentalmente válidos para o desenvolvimento de métodos e sistemas, operacionalizando as idéias em novos métodos, ao alcance dos objetivos dos artigos publicados. O único programa que praticamente abdicou deste tipo de pesquisa foi o Programa de Filosofia, cujo percentual de produção nessa área atingiu apenas $16,66 \%$. Nos demais Programas, este tipo de pesquisa atingiu um percentual de $23 \%$ ou acima.

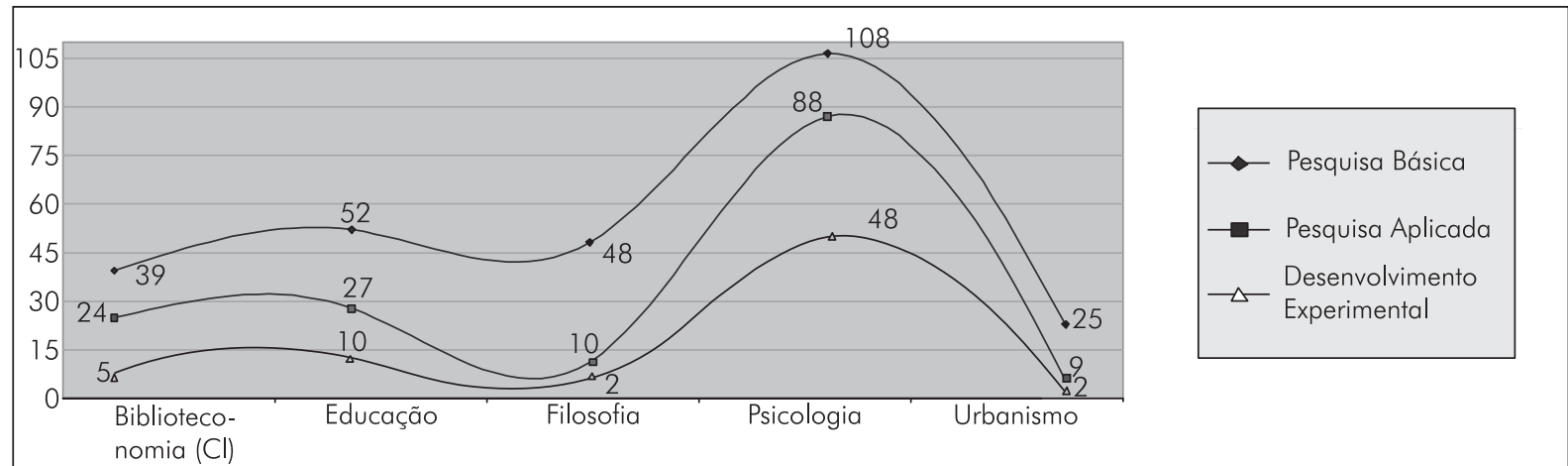

Figura 4. Tipo de Pesquisa desenvolvida nos Programas da PUC-Campinas.

Fonte: CNPq (Currículo Lattes). Dados trabalhados pelo autor. 
Finalmente, o último tipo de pesquisa estudado foi o desenvolvimento experimental, área em que os Programas, de forma em geral, apresentaram um percentual de produção abaixo dos $20 \%$. Isto explica-se, pelo fato de este tipo de pesquisa trabalhar, especificamente, com a aplicação de novos produtos, novos processos, sistemas e serviços, sendo que os programas estudados pouco atrelaram esta atividade aos seus interesses, fosse em virtude de terem uma relação muito forte com os demais tipos de pesquisa, fosse por não terem suporte estrutural ao desenvolvimento de produtos e sistemas - com raras exceções, como no segmento de desenvolvimento de softwares e programas computacionais.

\section{O N CLUS Ã O}

A partir das avaliações realizadas, podemos considerar que:

- A pesquisa dos docentes, a relação dos grupos de pesquisa, as produções individuais, além das orientações das dissertações e teses defendidas no período, foram satisfatórias, no que diz respeito à vinculação com as linhas de pesquisa. Foram estudados 25 grupos de pesquisa e $90 \%$ desses grupos atrelavam-se às linhas de pesquisa - somente dois grupos (em Educação e Psicologia) não conseguiram justificar a sua permanência em qualquer linha de pesquisa do seu respectivo programa de pós-graduação.

- A análise da vinculação da produção docente com as linhas de pesquisa, conforme objetivo específico, demonstrou que nenhum docente publicou fora dos moldes dos programas, tendo sempre a produção mais elevada em pelo menos uma linha de investigação de cada programa; constatou-se nesta análise que as linhas de pesquisa mais produtivas foram as de temáticas mais amplas, que contemplavam maior número de docentes;

- Em relação à orientação das dissertações e teses defendidas no período estudado, constatou- -se que o número das orientações foi relativamente baixo, pois, de todos os programas estudados, os índices não chegaram a três orientandos por docente, excetuando-se o Programa de Psicologia, que conseguiu chegar próximo a esta marca;

- Em relação aos trabalhos apresentados em congressos, constatou-se que um grande número destes trabalhos não se publicou como artigo científico; entretanto observou-se, como um fato inusitado, que boa parte dos trabalhos apresentados nesses eventos são de grande importância para os grupos de pesquisa, explicando a grande representação regional dos trabalhos;

- Foi constatado também que a Pesquisa Básica foi tipo investigação mais utilizada.

A produção científica na PUC-Campinas, de modo geral foi satisfatória, com um saldo positivo nos últimos anos analisados, em que houve um crescimento significativo, indicando uma ascensão na ciência dos Programas estudados.

Este trabalho também teve a pretensão de estudar a produção científica da instituição em questão dentro da base de conhecimento Pascal, para poder-se realizar uma comparação de produtividade da instituição frente à ISI; infelizmente, por motivos de falta de tempo e acesso à base citada, não foi possível tal análise.

Outro ponto a ser analisado, seria o consumo de informação, a partir das produções científicas utilizadas pelos docentes; entretanto, isto não foi possível, devido ao número de publicações envolvidas (artigos, trabalhos apresentados em eventos), ficando aqui sugerido este tema para "futura" investigação.

Note-se que todos os pontos analisados neste trabalho podem servir de referências iniciais para orientar a PUC-Campinas ao publicar sua produção científica em forma de memória de investigação; isto possibilitaria à instituição consolidar-se como líder na produtividade científica entre as instituições privadas do Estado de São Paulo e até competir, de igual para igual, com algumas universidades públicas federais.

\section{REFERÊNCIAS}

CAMARGO, D.M. As políticas de ciência e tecnologia: a inserção da PUC-Campinas no contexto nacional. Campinas: PUC-Campinas, 2002. (Projeto de Pesquisa-2003/2004). 
from: <http://www.garfield.library.upenn.edu/papers/ science_v122(3159)p108y1955.html>. Acess: 15 May 2002.

GOLDSCHMIDT, D. Estudos de Pós-graduação naAlemanha. Documento de trabalho NUPES - Estudo sobre Pós-Graduação, n.10. Universidade de São Paulo. São Paulo; 1996. 17p.

OCDE. Manual de Frascati: propuesta de norma práctica para encuestas de investigación y desarrollo experimental. Paris: OCDE, 1975.

PRICE, D.J.S. Little science, big science. New York: Columbia University Press, 1963.

PONTIFÍCIAUNIVERSIDADE CATÓLICADE CAMPINAS. Uma história, muitas vidas. Revista Comemorativa dos 60 Anos da Pontifícia Universidade Católica de Campinas. Campinas, 2002.

ROUSSEAU, R. Indicadores bibliométricos e econométricos para a avaliação de instituições científicas. Ciência da Informação, Brasília, v.27, n.2, p.149-158, 1998.
SCHWARTZMAN, S. Repensando o desenvolvimento: educação, ciência, tecnologia. In: Seminário - Desenvolvimento e a Política de Desenvolvimento, Instituto Goethe - IDESP, São Paulo, 18 e 19 de maio de 1993. Disponível em: <http:// www.schwartzman.org.br/simon/goethe.htm>. Acesso em: 20 out. 2003.

SPINAK, E. Indicadores cienciométricos. Ciência da Informação, Brasília, v.27, n.2, p.141-148, 1998.

TRINDADE, H. (Org.). Universidade em ruínas: na república dos professores. Petrópolis: Vozes, 1999.

VELHO, L.M.L.S. Como medir A ciência? Revista da Sociedade Brasileira de Ciência e Tecnologia de Alimentos, Brasília, v.16, n.1, p.35-41, 1985.

ZANOTTO, E.D. A defasagem entre a ciência e a tecnologia nacionais. Pesquisa FAPESP, São Paulo, n.43, 1999. Disponível em: <http://watson.FAPESP.br/nuplitec/patenteA.htm>. Acesso em: 25 out. 2003. 